\title{
Low-valent dialkoxytitanium(II): a useful tool for the synthesis of functionalized seven-membered ring compounds
}

-+Received 00th January 20xx,

\author{
Florent Bodinier ${ }^{a}$, Youssouf Sanogo ${ }^{a}$, Janick Ardisson ${ }^{a}$, Marie-Isabelle Lannou ${ }^{a}$, Geoffroy Sorin ${ }^{* a}$
}

Accepted 00th January 20xx

DOI: $10.1039 / x 0 x \times 00000 x$

Herein, we describe an unprecedented access to all-carbon or heterocyclic seven-membered ring frameworks from 1,8-ene-ynes promoted by inexpensive low-valent titanium(II) species, readily available from $\mathrm{Ti}(\mathrm{O} i \mathrm{Pr})_{4}$ and Grignard reagent. A broad range of cycloheptane, azepane or oxepane derivatives has been obtained (19 examples) with moderate to good yields and an excellent selectivity (up to $95 / 5$ d.r.).

Natural products synthesis is a tremendous source of inspiration and creativity. Faced with the molecular complexity and diversity encountered in nature, a synthetic chemist has to find innovative tools to tackle these problems. ${ }^{[1]}$ In this area, the construction of seven-membered ring frameworks, which are represented in numerous natural compounds or pharmaceuticals (Fig.1), appears to be a compelling challenge. ${ }^{[2]}$

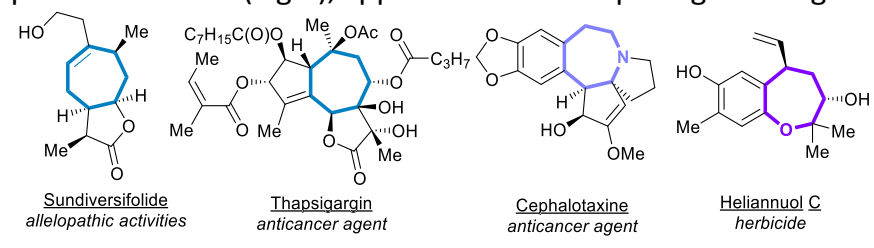

Fig.1 Natural compounds containing a seven-membered ring framework

Ring expansions [3] or ring closing reactions mediated by a transition metal catalyst are among the classical methods employed for the access to such structures. For example, gold, ${ }^{[4]}$ ruthenium, ${ }^{[5]}$ palladium, ${ }^{[6]}$ rhodium ${ }^{[7]}$ or iridium ${ }^{[8]}$ catalysts have already proven their efficiency in the construction of sevenmembered rings. Even though these processes allow a straightforward access to such cycles, they often require an expensive catalyst, tedious reaction conditions, or sophisticated precursors involving multistep sequences. Regarding the available methods, for economic and chemoselectivity issues as well as environmental concerns, designing new routes to sevenmembered ring adducts remains a significant challenge.

\footnotetext{
a. Unité CNRS UMR 8038 Université de Paris, Faculté de Pharmacie, Sorbonne Paris Cité, 4 avenue de l'Observatoire, 75270 PARIS cedex 06, (France)

+Electronic Supplementary Information (ESI) available: Experimental procedure, Compounds analysis, NMR spectra. See DOI: 10.1039/x0xx00000x
}

Titanium is a very abundant element in nature ( $9^{\text {th }}$ of the Earth's crust). In addition to its low cost, commercially available titanium alkoxides are non-toxic and eco-friendly. Since the beginning of the 1990s, chemistry of low-valent dialkoxytitanium(II) has known significant advances thanks to the Kulinkovich cyclopropanation. ${ }^{[9]}$ It was further established that $\mathrm{Ti}(\mathrm{II})$ divalent complexes were also suitable for promoting various reductive cyclization reactions, ${ }^{[10]}$ leading to five- and six-membered rings by a ligand exchange occurring at the preliminary step with $\pi$-systems, for example alkynes. ${ }^{[11]}$ More recently, first results mentioning low-valent titanium(II) mediated seven-membered rings syntheses were published. Hence, in 2001, Sato et al. reported an intramolecular reductive alkyne-alkyne coupling leading to a fused [4-7] bicycle.[12] Micalizio and co-workers published, in 2019, an elegant transformation involving low-valent dialkoxytitanium (II) for an access to highly functionalized fused polycyclic structures. ${ }^{[13]}$ In this manner, several types of polycycles, including sevenmembered rings, are thus reachable through a tandem annulative process between an alkyne and two ketones (Scheme 1).

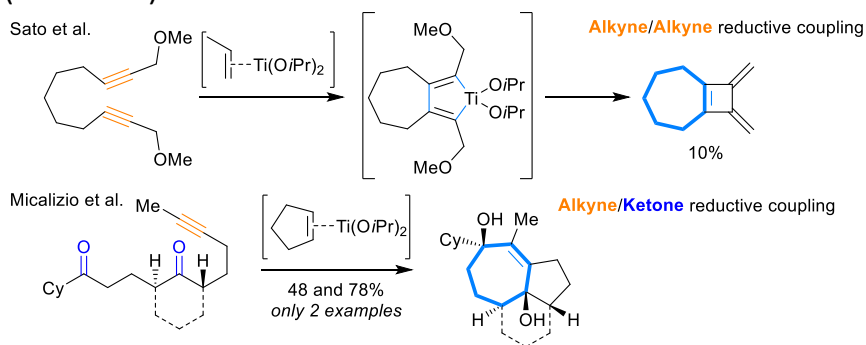

Scheme 1 Titanium(II) mediated synthesis of seven-membered rings

Inspired by the seminal works of Sato on various cyclization reactions involving ene-yne systems leading to five- and sixmembered rings ${ }^{[14]}$ we were delighted to discover, in the course of total synthesis of thapsigargin core, that $\mathrm{Ti}(\mathrm{II})$ was able to promote the diastereoselective formation of seven-membered rings through a reductive coupling process between an alkyne and an alkene. ${ }^{[15]}$ Encouraged by this preliminary result, we decided to pursue our investigations in order to determine the scope and limitations of such a transformation (Scheme 2). 


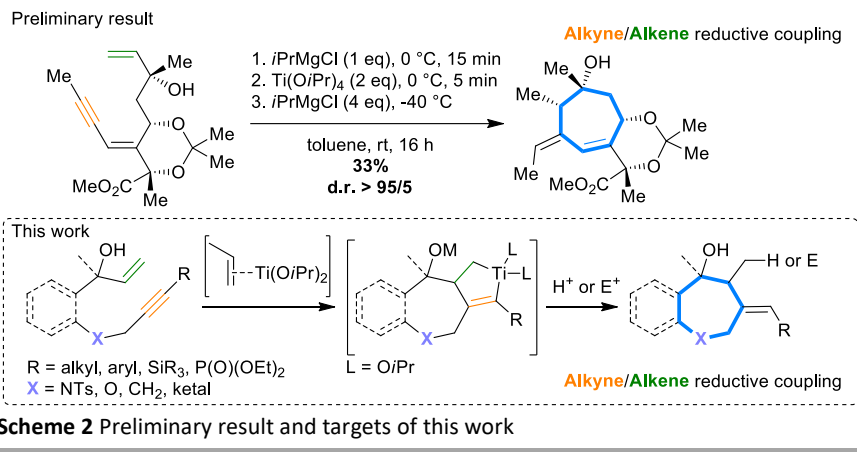

We started by the synthesis of the racemic cyclization precursor 1 from phthalic anhydride. After a seven steps linear sequence, the appropriate 1,8-alkene-yne system was obtained.[16] With the support of our preliminary result, ${ }^{[15]}$ we first investigated the best conditions to promote this cyclization (Table 1). ${ }^{[17]}$ Experimental procedure involves three steps : the first one corresponds to the deprotonation of free alcohol function (step 1), by means of an organolithium or magnesium reagent, followed by addition of a Ti(IV) source (step 2 ) then generation of the Ti(II) active species (step 3 ) using an organolithium or magnesium reagent.

Table 1 Optimization of reaction parameters

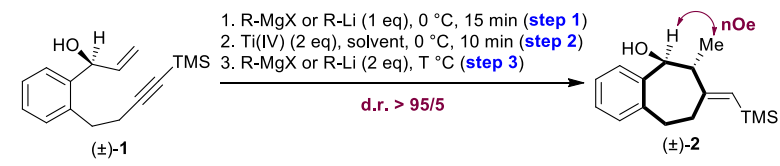

\begin{tabular}{|c|c|c|c|c|c|}
\hline $\begin{array}{c}\text { Entr } \\
\mathrm{y}\end{array}$ & Catalyst & Reductant & Solvent & Temp. & Yield(a) $^{(a)}$ \\
\hline 1 & $\mathrm{Ti}(\mathrm{O} i \mathrm{Pr})_{4}$ & iPrMgCl & Toluene & $\mathrm{rt}$ & $59 \%$ \\
\hline 2 & $\mathrm{TiCl}_{2} \mathrm{Cp}_{2}$ & iPrMgCl & Toluene & $\mathrm{rt}$ & $0 \%$ \\
\hline 3 & $\mathrm{TiCl}(\mathrm{O} i \mathrm{Pr})_{3}$ & iPrMgCl & Toluene & $\mathrm{rt}$ & $33 \%$ \\
\hline $4^{(\mathrm{b})}$ & $\mathrm{Ti}(\mathrm{OiPr})_{4}$ & iPrMgCl & Toluene & $\mathrm{rt}$ & $0 \%$ \\
\hline 5 & $\mathrm{Ti}(\mathrm{OiPr})_{4}$ & $n$ BuLi & Toluene & $\mathrm{rt}$ & $0 \%$ \\
\hline 6 & $\mathrm{Ti}(\mathrm{OiPr})_{4}$ & $\frac{\text { cpentylMgB }}{r}$ & Toluene & $\mathrm{rt}$ & $0 \%$ \\
\hline 7 & $\mathrm{Ti}(\mathrm{OiPr})_{4}$ & iPrMgCl & $\mathrm{Et}_{2} \mathrm{O}$ & $\mathrm{rt}$ & $32 \%$ \\
\hline 8 & $\mathrm{Ti}(\mathrm{OiPr})_{4}$ & iPrMgCl & THF & $\mathrm{rt}$ & $34 \%$ \\
\hline 9 & $\mathrm{Ti}(\mathrm{OiPr})_{4}$ & iPrMgCl & Toluene & $-40^{\circ} \mathrm{C}$ & $0 \%$ \\
\hline 10 & $\mathrm{Ti}(\mathrm{O} i \mathrm{Pr})_{4}$ & iPrMgCl & Toluene & $-20^{\circ} \mathrm{C}$ & $20 \%$ \\
\hline 11 & $\mathrm{Ti}(\mathrm{OiPr})_{4}$ & iPrMgCl & Toluene & $0^{\circ} \mathrm{C}$ & $43 \%$ \\
\hline 12 & $\mathrm{Ti}(\mathrm{OiPr})_{4}$ & iPrMgCl & Toluene & $45^{\circ} \mathrm{C}$ & $57 \%$ \\
\hline $13^{\text {(c) }}$ & $\mathrm{Ti}(\mathrm{O} i \mathrm{Pr})_{4}$ & iPrMgCl & Toluene & rt & $64 \%(60 \%)^{(d)}$ \\
\hline
\end{tabular}

(a) ${ }^{1} \mathrm{H}$-NMR yield was determined from 1,3,5-trimethoxybenzene as internal standard. (b) 1 equiv. of $\mathrm{Ti}(\mathrm{O} i \mathrm{Pr})_{4}$ and 2 equiv. of $i \mathrm{PrMgCl}$ were employed. (c) Respectively $6 \mathrm{~min}$. and $4 \mathrm{~min}$. instead of $15 \mathrm{~min}$. and $10 \mathrm{~min}$. were used for steps 1 and 2. (d) Isolated Yield.

First, deprotonation step (step 1) turned out to be essential. No reaction occured without deprotonating the alcohol group. Generation of sodium alcoholate was unsuitable since the alkyne was desilylated. Lithium alcoholate allows the process to occur (44\%) but not in a clean manner. ${ }^{[17]}$ Magnesium alcoholate from deprotonation with $i \mathrm{PrMgCl}$ was thus the most appropriate method. A brief screening of common Ti(IV) reagents (step 2) showed that $\mathrm{Ti}(\mathrm{O} i \mathrm{Pr})_{4}$ was the most suitable precursor (entry 1, 2 and 3 ) yielding to ( \pm )-2 in $59 \%$ yield (entry
1). Interestingly, using stoichiometric amount of $\mathrm{Ti}(\mathrm{OiPr})_{4}$ had a detrimental effect (entry 4), similarly, other reducing agents like $n$ BuLi (entry 5) or cpentylMgBr (entry 6) proved to be inappropriate and only degradation was observed. When the reaction was conducted in ethereal solvents such as THF (entry 7) or $\mathrm{Et}_{2} \mathrm{O}$ (entry 8 ), instead of toluene, yields respectively dropped to 32 and $34 \%$. We next examined the influence of the temperature on the cyclization (step 3). Running the reaction at $-40{ }^{\circ} \mathrm{C}$ afforded $( \pm)-2$ as traces with degradation side-products. At $-20{ }^{\circ} \mathrm{C}$ and $0{ }^{\circ} \mathrm{C}$, yields respectively rise to $20 \%$ (entry 10 ) and $43 \%$ (entry 11 ) still along with degradation side-products whereas increasing the temperature to $45{ }^{\circ} \mathrm{C}$ delivered ( \pm )-2 in a clean manner (entry $12,57 \%$ ). It is worth to mention that performing the reaction at room temperature or $45{ }^{\circ} \mathrm{C}$ turned out to be crucial for a clean and complete conversion. Finally, by shortening the deprotonation time (step 1) and the $\mathrm{Ti}(\mathrm{OiPr})_{4}$ mixing time (step 2), the yield was improved to $64 \%$ (entry 13 , $60 \%$ isolated yield and $40 \%$ on $1.5 \mathrm{mmol}$ scale) while maintaining an excellent stereoselectivity in favour of the transadduct (d.r. > 95/5). It should be mentioned that the brief mixing time of alcoholate with Ti(IV) (step 2) is essential. Indeed, the direct generation of $\mathrm{Ti}(\mathrm{II})$ after addition of $\mathrm{Ti}(\mathrm{O} i \mathrm{Pr})_{4}$ led to a modest yield (33\%) and a loss of the selectivity. ${ }^{[17]}$

With the best conditions in hand, we studied the scope and limitations of the reaction on several structural derivatives of 2 (Scheme 3). First, we investigated the influence of the substitution pattern on the alkyne. Precursor 3 bearing a bulky TBS group yielded the cyclized product $(4,55 \%)$ with an excellent selectivity. Introducing an alkyl instead of a silyl group such as a methyl group (5) resulted in a slight decrease in yield $(6,48 \%)$. Alkyne bearing phenyl (7) or $p$-methoxyphenyl group (9) respectively afforded 8 and $\mathbf{1 0}$ in good yield (60\% and 49\%). Interestingly, these conditions were also found suitable for alkynylphosphonate ${ }^{[18]}$ (11) even if the expected product was obtained (12) in moderate yield (31\%) along with degradation side-products. Noteworthy, in all cases, an excellent selectivity toward the trans-isomer was observed (d.r. > 95/5).

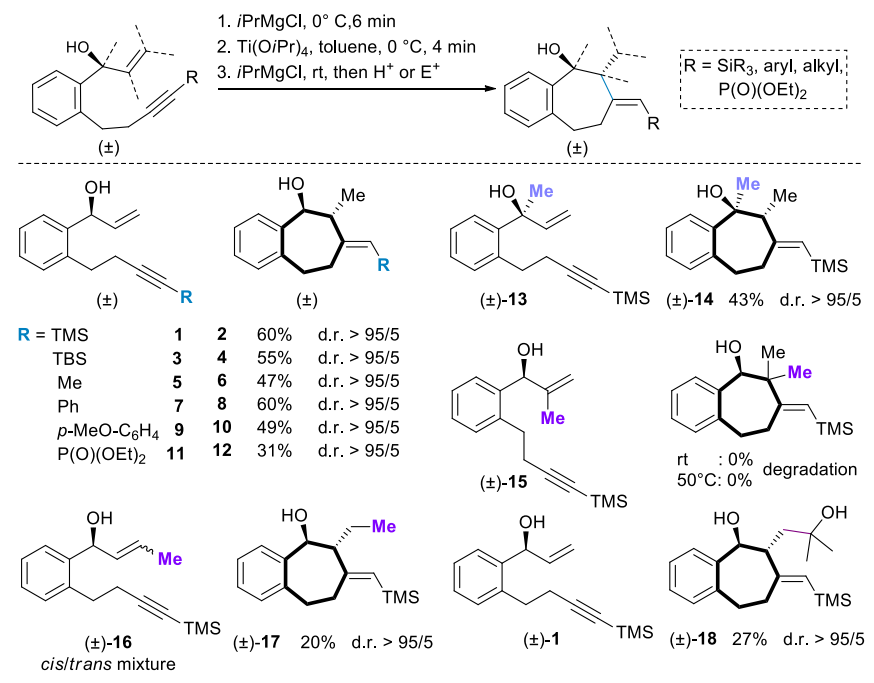

Scheme 3 Cyclization reaction onto ene-yne containing phenyl framework.

Compound 13, containing a tertiary methyl- vinyl- alcohol, structurally close to the cyclization precursor of thapsigargin core firstly engaged with low-valent dialkoxytitanium(II),[13] provided the corresponding seven-membered ring adduct 14 in 
modest yield (43\%) with a total diastereoselectivity in favour of the trans-isomer. Finally, we surveyed the substitution of the alkene moiety. Compound $\mathbf{1 5}$ bearing internal methyl substituent onto the double bond, was reluctant to cyclize under our conditions, even in a prolonged reaction time or by heating at $50{ }^{\circ} \mathrm{C}$. From an inseparable cis/trans mixture (36/64) of the precursor 16 , only $20 \%$ of the desired product 17 was obtained as well as the alkyne reduction product $(\sim 14 \%$ with side products). These results could be explained by a steric hindrance between the alkene moiety and the titanacycloproprene intermediate, which precludes the ring closure. Concerning compound 16, we hypothesized that only the cis isomer was able to cyclize explaining the poor yield. Indeed, Sato et al. have already evidenced that such cyclization was highly sensitive to the geometry of the double bond. [14c] Finally, the conditions developed herein allowed the trapping of electrophiles like acetone (18, 27\%). However, the yield was disappointingly low, which is probably due to a competitive deprotonation in $\alpha$-position to the ketone moiety by the intermediate titanacyclopentene since a large amount of compound $\mathbf{2}$ was recovered at the end of the reaction.

All the cyclization reactions gathered in Scheme 2 led to excellent selectivity in favour of the trans-isomer. We presumed that the diastereoselectivity observed would arise from the free allylic alcohol. ${ }^{[19]}$ Indeed, its directing effect in the cyclization of enynol and allenynols systems has already been underlined. ${ }^{[20]}$ Moreover, the need to keep a short mixing time with two equivalents of $\mathrm{Ti}(\mathrm{IV})$ could witness the real implication of the alcohol toward the selectivity observed through an interaction with one equivalent of titanium reagent. In order to assess this assumption regarding seven-membered ring adducts, we ran two control reactions with the vinylic alcohol protected as a silylated ether (19) or a methyl ether (20) (Scheme 4).

The cyclization reaction conducted onto TBS ether provided poor selectivity (ratio: $37 / 63$ ) and yield $(12 \%$ and $21 \%$ as determined by ${ }^{1} \mathrm{H}$ NMR) along with reduction of the alkyne moiety $\left(20,20 \%\right.$ as determined by ${ }^{1} \mathrm{H}$ NMR) and numerous others inseparable undefined side products. In a similar manner, an important drop in yield and selectivity was observed when the reaction was performed onto methyl-ether 21. However, we were pleased to isolate the 8-membered ring adduct $(22,38 \%)$ as the major product, which would probably result from a $\mathrm{S}_{\mathrm{N}} 2^{\prime}$ mechanism.

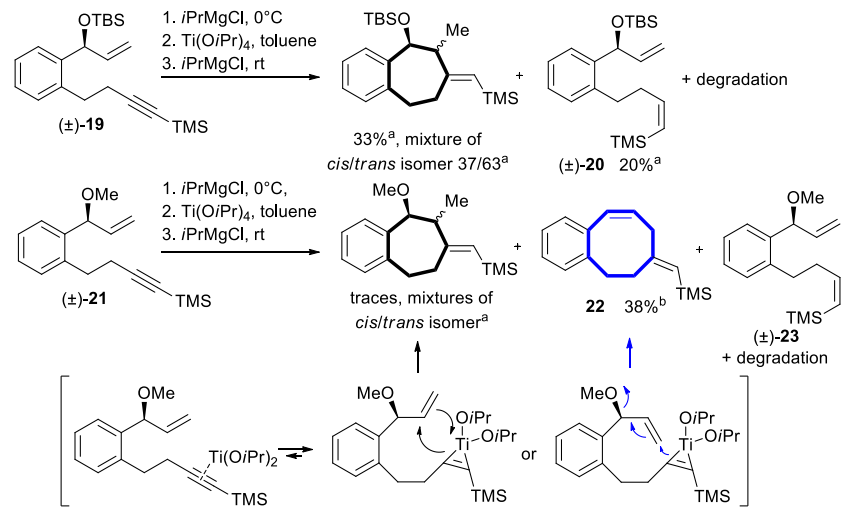

a ${ }^{1} \mathrm{H}$ NMR conversion calculated from 1,3,5-trimethoxybenzene as internal standard. ${ }^{b}$ Isolated yield.

Scheme 4 Influence of the protecting group on allylic alcohol

As a conclusion, the presence of a free alcohol in the allylic position seems to play a crucial role onto both selectivity and yield. Hence, less side reaction products were observed when substrates comporting a free allylic alcohol were involved compared to their homologues bearing a protected alcohol, free hydroxy group would then help to prevent side reactions. For these reasons, we pursued our scope investigation from allylic alcohol-type compounds.

We first regarded all-carbon chain containing ene-yne systems like 24, 26 and 28 (Scheme 5).

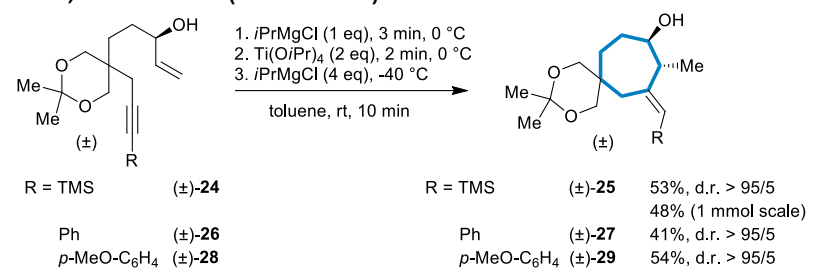

Scheme $\mathbf{5}$ Synthesis of cycloheptane derivatives

The conditions turned out to be suitable for $\mathbf{2 4 , 2 6}$ and $\mathbf{2 8}$ and good yields were obtained respectively for $\mathbf{2 5}$ (53\% and $48 \%$ on $1 \mathrm{mmol}$ scale), $27(41 \%)$ and $29(54 \%)$ as well as excellent diastereoselectivities (up to 95/5). However, it is important to mention that the time for step 2 was shortened in order to circumscribe side reactions between Ti(IV) and the ketal moiety. This reaction can also be extended to $\mathrm{N}$ - or $\mathrm{O}$ - containing substrates in order to access to azepane (Scheme 6) or oxepane derivatives (Scheme 7).

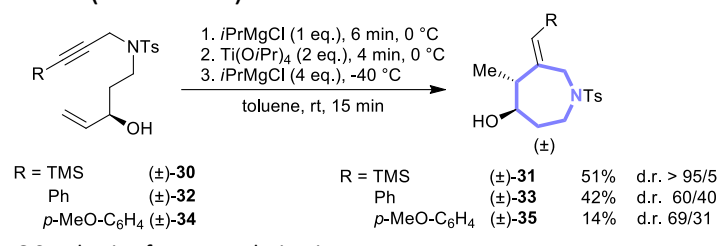

Scheme 6 Synthesis of azepane derivatives

We were pleased to observe good conversion and selectivity from $\mathbf{3 0}$ offering the azepane derivatives $\mathbf{3 1}$ in moderate yield (51\%). Intriguingly, replacing TMS group by a phenyl (32) or $p$ methoxyphenyl group (34) onto the alkyne led to a drop in yield (33, 42\% and 35, 14\%) and selectivity (33, 60/40 and 35, 69/31). Although the yield was modest $(27 \%)$, it was also possible to trap the titanabicycle intermediate by a ketone ${ }^{[19]}$. Thus, the expected product 36, was obtained from 30, with an excellent diastereoselectivity in favour of the trans-isomer.

We finally carried out the cyclization reaction on compounds $\mathbf{3 7}$ and 39 and we were delighted to respectively obtain the corresponding oxepane derivatives 38 (43\%) and $40(28 \%)$ (Scheme 7).

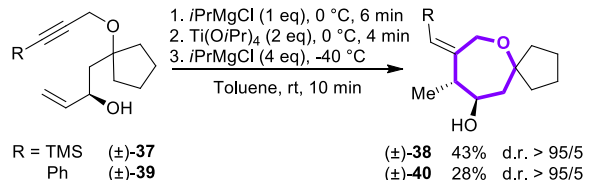

Scheme 7 Synthesis of oxepane derivatives and assumed elimination mechanism

Astonishingly, conducting the reaction on $\mathbf{3 7}$ over a prolonged time (20 min. instead of $10 \mathrm{~min}$.) decreased the yield to $19 \%$. At the purification step, diol $\mathbf{4 2}$ was isolated with a modest yield $(16 \%)^{[19]}$. The presence of this product could explain the disappointing yield in cyclization adduct 18. Indeed, if the elimination of a leaving group at the $\alpha$-position of a titanacyclopropene is well known, ${ }^{[21]}$ the critical drop of the yield over a longer reaction time allows to presume that the 
expected cyclization process occurs first and the titanabicycle 41 intermediate undergoes an irreversible competitive elimination process leading to diol 42. ${ }^{[22]}$ Thenceforth, a rapid quench of the intermediate, after $10 \mathrm{~min}$ as described, is required in order to limit this undesired pathway.

\section{Conclusion}

In summary, we have extended the intramolecular low-valent dialkoxytitanium(II) mediated cyclization reaction of ene-yne systems to seven-membered ring compounds with moderate to good yields. In most cases, a very good selectivity in favour of the trans-isomer was obtained. The conditions developed herein are mild, easy to set-up, relying on the use of inexpensive $\mathrm{Ti}(\mathrm{OiPr})_{4}$ and the cyclic adducts are obtained after a short time ( $10 \mathrm{~min}$ ) as a single diastereoisomer. Thanks to the conditions established, we were able to reach various (hetero)cycles i.e. cycloheptane as well as azepane or oxepane frameworks in a single step. We also highlighted the crucial role of the free allylic alcohol regarding the selectivity and the yield of the cyclization reaction. Thanks to the titanabicyclic intermediate, a complete control of the exocyclic double bond geometry is also to mention in all cases. Finally, we demonstrated the possibility to access 8-membered rings in moderate yield through a $\mathrm{S}_{\mathrm{N}} 2^{\prime}$ mechanism, which could open the way to the synthesis of larger cycles. Thus, the conditions need to be optimized and are currently undergoing in our laboratory.

\section{Conflicts of interest}

There are no conflicts to declare.

\section{Notes and references}

1 For recent representative reviews on total synthesis, see: (a) L. Li, Z. Chen, X. Zhang, Y. Jia, Chem. Rev., 2018, 118, 37523832. (b) J. E. Zweig, D.E. Kim, T. R. Newhouse, Chem. Rev., 2017, 117, 11680-11752. (c) L. W. Hernandez, D. Sarlah, Chem. Eur. J., 2019, 25, 13248-13270. (d) R. W. Hoffmann, Angew. Chem. Int. Ed., 2013, 52, 123-130. (e) K. C. Nicolaou, J. S. Chen, Chem. Soc. Rev., 2009, 38, 2993-3009.

2 For selected book chapters or articles on synthesis of seven membered rings, see: (a) J. Ryan, J. Green, C. Hyland, J. Smith, C. Williams. Seven-membered rings. In: Gordon W. Gribble and John A. Joule, editor/s. Progress in Heterocyclic Chemistry. Great Britain: Elsevier; 2011. 465-504; (b) K. T.de Oliveira, B. M. Servilha L. C. Alves, A. L. Desiderá, T. J. Brocksom, The synthesis of seven-membered rings in natural products. In: Atta-ur-Rahman editor. Studies in Natural Product Chemistry. Great Britain: Elsevier; 2014. 421-463.

3 For some representative examples, see: (a) S. Bastos Lemos Silva, A. Della Torre, J. Ernesto de Carvalho, A. L. Tasca Gois Ruiz, L. F. Silva Jr. Molecules, 2015, 20, 1475-1494. (b) Z.-L. Song, C.-A. Fan, Y.-Q. Tu, Chem. Rev., 2011, 111, 7523-7556. (c) B. C. Kang, S. Y. Shim, D. H. Ryu, Org. Lett., 2014, 16, 20772079.

4 From gold catalyst see for example: (a) H. Ito, H. Ohmiya, M. Sawamura, Org. Lett., 2010, 12, 4380-4383. (b) H. Tinnermann, L. D. M. Nicholls, T. Johannsen, C. Wille, C. Golz, R. Goddard, M. Alcarazo, ACS Catal., 2018, 8, 10457-10463.

5 From ruthenium catalyst see for example: (a) A. LópezRodríguez, G. Domínguez, J. Pérez-Castells, J. Org. Chem. 2019, 84, 924-933. (b) S. P. Andrews, M. Ball, F. Wierschem, E.
Cleator, S. Oliver, K. Högenauer, O. Simic, A. Antonello, U. Hünger, M. D. Smith, S. V. Ley, Chem. Eur. J., 2007, 13, 56885712.

6 From palladium catalyst see for example: (a) A. A. Peshkov, V. A. Peshkov, O. P. Pereshivko, K. V. Hecke, R. Kumar, E. V. Van der Eycken, J. Org. Chem., 2015, 80, 6598-6608. (b) C. Zhu, B. Yang, B. K. Mai, S. Palazzotto, Y. Qiu, A. Gudmundsson, A. Ricke, F. Himo, J.-E. Bäckvall, J. Am. Chem. Soc., 2018, 140, 14324-14333.

7 From rhodium catalyst see for example: (a) A. Tap, C. Lecourt, S. Dhambri, M. Arnould, G. Galvani, O. Nguyen Van Buu, M. Jouanneau, J.-P. Férézou, J. Ardisson, M.-I. Lannou, G. Sorin, Chem. Eur. J., 2016, 22, 4938-4944. (b) F. Grillet, K. M. Brummond, J. Org. Chem., 2013, 78, 3737-3754.

8 From iridium catalyst see for example: D. F. Fernández, C. A B. Rodrigues, M. Calvelo, M. Gulías, J. L. Mascareñas, F. López, ACS Catal., 2018, 8, 7397-7402.

9 S. V. Sviridov, D. A. Vasilevski, T. S. Pritytskaya, O. G. Kulinkovich, Russ. J. Org. Chem., 1989, 25, 2027-2028.

10 For a review, see for example: (a) F. Sato, S. Okamoto, $A d v$. Synth. Catal., 2001, 343, 8, 759-784. (b) G. C. Micalizio, H. Mizoguchi, Isr. J. Chem., 2017, 57, 228-238.

11 For various representative examples, see: (a) A. Wolan, Y. Six, Tetrahedron, 2010, 66, 3097-3133. (b) M. Ohkubo, W. Ichikawa, H. Matsushita, A. Nakano, T. Shirato, S. Okamoto, Tetrahedron. Lett., 2006, 47, 5181-5185. (c) R. M. Leon, D. Ravi, J. S. An, C. L. del Genio, A. L. Rheingold, A. B. Gaur, G. C. Micalizio, Org. Lett., 2019, 21, 3193-3197. (d) A. B. Millham, M. J. Kier, R. M. Leon, R. Karmakar, Z. D. Stempel, G. C. Micalizio, Org. Lett., 2019, 21, 567-570.

12 C. Delas, H. Urabe, F. Sato, Tetrahedron Lett., 2001, 42, 41474150.

13 R. Karmakar, A. L. Rheingold, G. C. Micalizio, Org. Lett., 2019, 21, 6126-6129.

14 For some representative examples, see: (a) H. Urabe, T. Hata, F. Sato, Tetrahedron Lett., 1995, 36, 4261-4264. (b) K. Suzuki, H. Urabe, F. Sato, J. Am. Chem. Soc., 1996, 118, 8729-8730. (c) H. Urabe, K. Suzuki, F. Sato, J. Am. Chem. Soc., 1997, 119, 10014-10027.

For a review on Sato's works, see: (d) F. Sato, S. Okamoto, Adv. Synth. Catal. 2001, 343, 759-784.

15 Y. Sanogo, R. Ben Othman, S. Dhambri, M. Selkti, A. Jeuken, J. Prunet, J.-P. Férézou, J. Ardisson, M.-I. Lannou, G. Sorin, J. Org. Chem., 2019, 84, 5821-5830.

16 For the synthesis of cyclization precursors, see S.I.

17 For complete survey on optimization reaction, see S.I.

18 A. A. A. Quntar, O. Baum, A. Shibli, V. M. Dembitsky, M. Srebnik, Angew. Chem. Int. Ed., 2003, 42, 4777-4779.

19 For assumed mechanism and selectivity, see S.I.

20 For some representative examples, see: (a) W.A. Nugent, D. F. Taber, J. Am. Chem. Soc., 1989, 111, 6435-6437. (b) H. Urabe, F. Sato, Tetrahedron Lett., 1998, 39, 7329-7332.

21 (a) T. Nakagawa, A. Kasatkin, F. Sato, Tetrahedron Lett., 1995, 36, 3207-3210. (b) S. Okamoto, D. K. An, F. Sato, Tetrahedron Lett., 1998, 39, 4551-4554.

22 Due to its volatility, the resulting TMS-allene was not detected. 